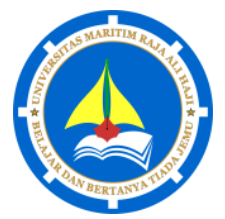

Jurnal Anugerah, 2(1) (2020)

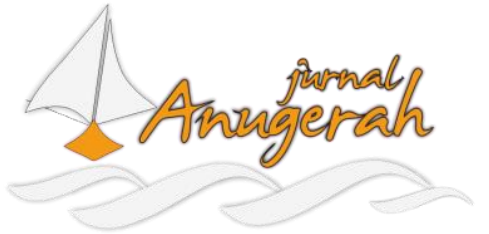

e-ISSN 2715-8179

https://ojs.umrah.ac.id/index.php/anugerah

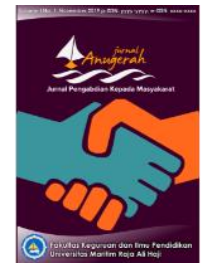

\title{
Penanaman Mangrove dengan Tema "Protect the Mangroves that Help Protect Our Island"
}

\author{
Bony Irawan ${ }^{1}$, Nurul Asikin ${ }^{2}$, Adam Fernando ${ }^{3 *}$ \\ 1, 2,3 Universitas Maritim Raja Ali Haji, Tanjungpinang, Provinsi Kepulauan Riau 29115, Indonesia \\ e-mail korespondensi: adamfernando@umrah.ac.id
}

Pengiriman: 6 April 2020; Diterima: 24 Mei 2020; Publikasi: 31 Mei 2020

DOI: https://doi.org/10.31629/anugerah.v2i1.2160

\begin{abstract}
Abstrak
Kota Tanjungpinang merupakan daerah pesisir yang menjadi dampak meningkatnya jumlah penduduk di kota Tanjungpinang seperti alih fungsi lahan sebagai lahan pemukiman, industri, pertambangan serta kegiatan lainnya. Beberapa kawasan mangrove di kota Tanjungpinang perlu diberikan perhatian yang lebih. Salah satunya melalui konservasi ekosistem mangrove. Kurangnya kesadaran masyarakat akan dampak rusaknya ekosistem mangrove di daerah pesisir menyebabkan permasalahan tersebut terus berlangsung. Oleh karena itu, dilakukan suatu tindakan seperti penanaman bibit mangrove di kawasan tersebut, sehingga kelangsungan hidup di kawasan ekosistem mangrove ini dapat terjaga kelestariannya. Berdasarkan permasalahan tersebut maka perlu dilakukan kegiatan pengabdian kepada masyarakat yaitu penanaman mangrove sebagai upaya meningkatkan kesadaran masyarakat dalam menjaga kawasan ekosistem mangrove dan menjaga kelestariannya.
\end{abstract}

Kata kunci: penanaman mangrove; mangrove; ekosistem mangrove

\begin{abstract}
Tanjungpinang is a coastal area. The impact of increasing population in the city such as the conversion of land as residential, industrial, mining and other activities. Some mangrove areas in the city need to be given more attention, one of them is through the conservation of mangrove ecosystems. Lack of public awareness about the impact of the mangrove ecosystems destruction in coastal areas causes these problems to continue. Therefore, it is necessary to take a real action such as planting mangrove seedlings in the area, so that survival in this mangrove ecosystem area can be preserved. Based on these problems, it is necessary to do community service activities such as planting mangroves as an effort to increase public awareness in protecting the mangrove ecosystem and maintaining its sustainability.
\end{abstract}

Keywords: Planting mangrove; mangrove; mangrove ecosystem

\section{Pendahuluan}

Provinsi Kepulauan Riau merupakan daerah pesisir yang sedang berkembang. Hal ini ditandai dengan meningkatnya jumlah penduduk. Berdasarkan data yang diperoleh Badan Pusat Statistik (BPS) tahun 2017 dan 2019, jumlah penduduk di Kepulauan Riau masing-masing sebesar 2.082.694 dan 2.189.653 jiwa. Peningkatan jumlah penduduk ini dapat berpengaruh terhadap banyaknya kerusakan lingkungan, termasuk kerusakan pada ekosistem mangrove. Ekosistem mangrove memiliki fungsi ekologis dan ekonomi. Fungsi ekologis dari ekosistem mangrove dapat menyediakan jasa lingkungannya sebagai wilayah strategis untuk mengkaji konsep-konsep ekologis yang dilakukan berbagai pihak, sedangkan fungsi ekonomisnya adalah 
melalui pengembangan ekowisata (Utina, Katili dan Retnowati, 2014). Kerusakan pada ekosistem mangrove dapat mengganggu kedua fungsi tersebut.

Ekosistem mangrove disusun oleh berbagai faktor biotik dan abiotik yang saling berinteraksi, sehingga terbentuklah hutan mangrove. Secara alami, kelangsungan hidup hutan mangrove dapat dipengaruhi oleh berbagai faktor. Mangrove memiliki ciri khas tersendiri. Mangrove dapat hidup di zona pasang surut sehingga kondisi dataran selalu digenangi oleh air. Kemudian, dari sistem perakarannya juga dapat melakukan osmoregulasi agar garam tidak masuk ke dalam tubuh. Pada saat pasang rendah, genangan air menjadi berkurang (Mustofa, 2018).

Menurut Noor, dkk (1999), vegetasi mangrove memiliki pola zonasi, yang berhubungan dengan tipe tanah (baik tanah lumpur, pasir atau gambut), terbuka terhadap hempasan gelombang, salinitas dan pengaruh pasang surut. Mangrove dikenal sebagai salah satu wilayah pesisir yang memiliki tingkat produktivitas tinggi. Bengen (2001) menjelaskan karakteristik hutan mangrove adalah:

a. Tumbuh pada daerah intertidal;

b. Wilayahnya tergenang air laut secara berkala;

c. Dapat menerima pasokan air tawar yang cukup dari darat, dan

d. Wilayahnya terlindungi dari arus pasang surut yang besar.

Hutan mangrove memiliki fungsi sebagai pengendapan lumpur di akar-akarnya sehingga dapat mencegah terjadinya intrusi air ke daratan. Selain itu, hutan mangrove juga berperan sebagai pencegah abrasi atau pengikisan bibir pantai. Hutan mangrove juga dapat mengembangkan dari segi ekonomi masyarakat dengan pengembangan ekowisata di sekitarnya. Manfaat ekosistem mangrove menurut Lasibani dan Eni (2009), adalah sebagai penahan gelombang air, pelindung arus pasang dan abrasi, penetral pencemaran air serta pencegah instrusi air.

Manfaat mangrove ini sering tidak disadari oleh masyarakat sehingga banyak terjadi kerusakan hutan mangrove, termasuk di daerah Kepulauan Riau. Banyak kasus perusakan mangrove di Indonesia, termasuk di Provinsi Kepulauan Riau. Menurut Sekretaris Badan Karantina Ikan, Pengendalian Mutu dan Keamanan Hasil Perikanan (BKIPM) RI, Septiama yang dikutip dari halaman online Gatracom (21/9/19) mengatakan, kerusakan mangrove di Indonesia sudah mencapai 40 hingga 60\%. Bahkan, mangrove yang tersisa di provinsi Kepulauan Riau hanya sekitar 40 persen.

Beberapa contoh hasil penelitian yang dilakukan oleh Utomo, dkk (2017) dapat disimpulkan bahwa dampak rehabilitasi mangrove adalah meningkatnya produksi ikan, dapat mengurangi abrasi, menahan angin dari laut ke darat, meningkatkan hasil penangkapan ikan, kepiting, udang dan kerang serta meningkatkan potensi objek wisata pantai. Kemudian, berdasarkan hasil observasi di lapangan, beberapa kawasan mangrove di Sungai Carang mengalami kerusakan akibat adanya lahan bekas pertambangan bauksit yang memberikan dampak terhadap vegetasi, seperti berubahnya struktur dan komposisi vegetasi (Ledheng dan Yustiningsih, 2018).

Secara umum, dampak ekologis akibat rusaknya ekosistem mangrove adalah menurunnya keanekaragaman hayati di dalam ekosistem mangrove, sehingga akan mengganggu keseimbangan ekosistem. Selain itu, terjadinya peningkatan potensi abrasi pada ekosistem mangrove, penurunan hasil penangkapan ikan, dan lainnya. Banyaknya aktivitas manusia yang merusak ekosistem mangrove seperti pengambilalihan lahan mangrove menjadi pemukiman, perkantoran dan sebagainya membuat ekosistem mangrove ini terancam kelestariannya.

Oleh karena itu, diperlukan suatu upaya yang dapat membantu ekosistem hutan mangrove tersebut dari berbagai ancaman. Salah satu upaya yang dapat dilakukan adalah dengan melakukan pemberdayaan masyarakat. Adanya keterlibatan masyarakat untuk melakukan rehabilitasi hutan mangrove sangat penting untuk dilakukan. Masyarakat harus diarahkan untuk menjaga kelestarian hutan mangrove salah satunya dengan aksi penanaman bibit mangrove. 
Pengelolaan dan perawatan kawasan konservasi hutan mangrove perlu mendapatkan perhatian yang lebih banyak. Salah satu upaya yang dapat dilakukan adalah penanaman bibit mangrove di lahan-lahan yang masih kosong. Penanaman bibit mangrove ini dapat dilakukan melalui pembentukan kelompok sadar lingkungan yang dapat melibatkan masyarakat sekitar yang sadar akan pentingnya menjaga kelestarian ekosistem mangrove. Adanya kawasan konservasi mangrove diharapkan mampu memperbaiki ekosistem serta mampu memberikan daya tarik edukasi wisata kawasan konservasi hutan mangrove. (Mulyani, Lewaru dan Haetami, 2018). Berdasarkan permasalahan tersebut maka perlu dilakukan kegiatan pengabdian kepada masyarakat yaitu penanaman mangrove dengan tema "Protect the Mangroves that Help Protect Our Island".

\section{Metode}

Kegiatan ini dilaksanakan dengan menggunakan metode edukasi dan penanaman mangrove yang bersinergi antara pihak perguruan tinggi, lembaga terkait maupun masyarakat secara bersama-sama. Kegiatan penanaman mangrove melibatkan mahasiswa, Banyan Tree Bintan dan Balai Pengelolaan Daerah Aliran Sungai dan Hutan Lindung (BPDASHL) Provinsi Kepulauan Riau sebagai mitra dalam kegiatan ini. Guru dan siswa dari beberapa sekolah juga terlibat langsung dalam kegiatan ini, serta dosen-dosen Program Studi Pendidikan Biologi UMRAH.

Kegiatan edukasi dan penanaman mangrove ini dilakukan pada tanggal 15 Desember 2019. Kegiatan edukasi bertujuan untuk memberikan pemahaman mengenai teknik penanaman mangrove serta menumbuhkan kesadaran pentingnya menjaga kelestarian ekosistem mangrove, khususnya di kawasan Sungai Carang Kota Tanjungpinang sebagai lokasi penanaman bibit mangrove. Kegiatan edukasi yang dilakukan adalah dengan memberikan penjelasan secara singkat kepada seluruh peserta mengenai cara menanam bibit mangrove yang baik dan benar, agar saat pelaksanaan kegiatan penanaman mangrove dapat berjalan dengan baik. Secara singkat, tahapan proses kegiatan penanaman mangrove yang dilaksanakan adalah:

\section{Tahap Persiapan}

Pada tahap persiapan dilakukan dengan melakukan survey lapangan untuk menentukan wilayah yang cocok untuk dilakukan penanaman mangrove ini. Selain itu, tim PKM juga mengambil data awal vegetasi berupa luas tutupan (cover) tanah yang akan ditanami mangrove pada wilayah yang akan ditentukan. Kemudian, tim beserta lembaga mitra juga mempersiapkan bibit mangrove yang akan ditanam sebanyak 1500 batang dari BPDASHL dan 1000 batang dari Banyan Tree Bintan. Setelah diperoleh wilayah yang cocok, kemudian tim PKM membuat jalur penanaman bibit mangrove berupa garis lurus di sepanjang wilayah tersebut seluas $500 \mathrm{~m}^{2}$.

\section{Tahap Pelaksanaan}

Pada tahap pelaksanaan, dilakukan penanaman bibit mangrove yang telah disediakan sesuai dengan arahan atau edukasi yang dilakukan sebelumnya. Rencana penanaman mangrove ini dilakukan pada pukul 08.00 WIB.

\section{Hasil dan Pembahasan}

\section{Persiapan \\ Kegiatan penanaman mangrove ini dilakukan dalam dua tahapan, yaitu:}

Pada tahap persiapan ini dilakukan survey lapangan untuk menentukan wilayah mana yang akan dijadikan lokasi penanaman bibit mangrove. Berdasarkan hasil survey, diperoleh lokasi penanaman mangrove yang cocok adalah di kawasan Sungai Carang. Kemudian, data awal vegetasi yang telah diamati diperoleh luas tutupan (cover) terhadap tanah yang diamati pada daerah penanaman awalnya hanya terdapat tanah bekas pertambangan bauksit saja, sehingga memungkinkan kegiatan penanaman ini dapat dilakukan. Adapun wilayah lokasi penanaman mangrove dapat dilihat pada gambar 1. 


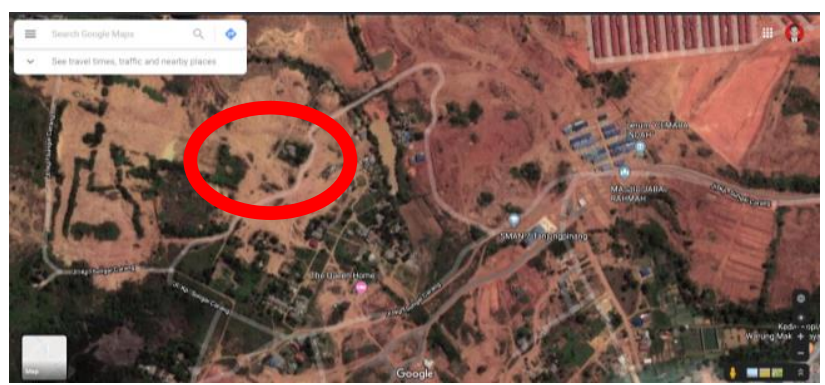

Gambar 1. Peta lokasi kegiatan penanaman mangrove di kawasan Sungai Carang (lingkar merah)

\section{Pelaksanaan Kegiatan}

Kegiatan penanaman mangrove ini dilakukan pada tanggal 15 Desember 2019. Bibit mangrove yang ditanam sebanyak 2500 bibit yang diperoleh melalui dukungan dari Banyan Tree Bintan dan BPDASHL. Penanaman mangrove ini dilakukan pada saat pasang surut di pagi hari agar penanaman bibitnya lebih mudah. Penanaman mangrove dilakukan dengan mengikuti jalur yang telah disediakan oleh panitia pelaksana agar penanamannya tidak berantakan. Namun, pada saat penanaman bibit berlangsung ternyata pasang naik sekitar jam 09.30-12.00 WIB. Awalnya penanaman bibit mangrove dilakukan sesuai dengan jalur yang telah dibuat, tetapi saat pasang naik peserta kesulitan menanamnya. Untuk mengatasi hal tersebut, tim PKM mengarahkan para peserta untuk bekerja sama menanam bibit secara perlahan-lahan dengan saling berpegang tangan agar tidak tergelincir saat melangkah pada tanah pijakannya. Berkat bantuan dan dukungan dari beberapa orang ahli yang ikut terlibat, penanaman dapat dilakukan kembali sesuai dengan rencana. Berikut ini adalah dokumentasi kegiatan penanaman mangrove yang telah dilaksanakan.
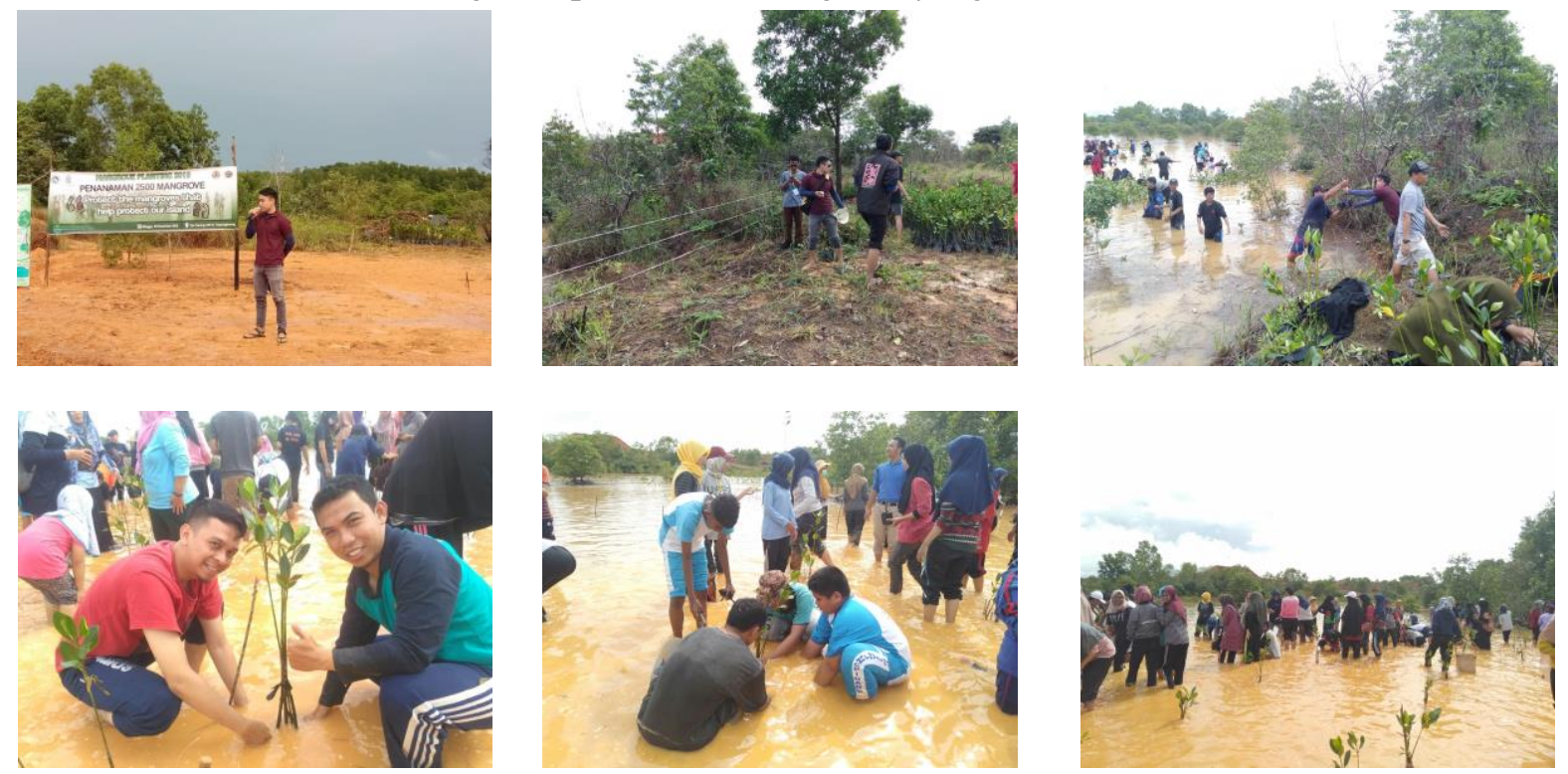

Gambar 2. Pelaksanaan kegiatan penanaman mangrove di kawasan Sungai Carang

Kegiatan penanaman mangrove ini dilakukan melalui beberapa tahapan yang dirujuk melalui Irawan (2014), yaitu:

a. Membuat titik acuan penanaman bibit mangrove untuk memudahkan peserta saat menanam bibit mangrove yang diberikan;

b. Melakukan penanaman bibit mangrove dengan metode praktik langsung di lokasi penanaman. Pola penanaman bibit mangrove dilakukan dengan pola penanaman bertumpuk. Pada satu titik acuan ditanam sebanyak lima benih mangrove. Menurut Irawan (2014), kemungkinan bertahan hidup bibit 
mangrove sekitar 30-80\%, sehingga diperlukan bibit sekitar 3-5 bibit agar dapat tumbuh dan berkembang dengan baik;

c. Memberikan jarak tanam sejauh 1 meter. Menurut Irawan (2014), pemberian jarak tanam bibit mangrove bertujuan untuk konservasi, sehingga diharapkan bibit mangrove yang ditanam tumbuh pada jarak yang rapat. Mangrove yang rapat dapat berfungsi sebagai penahan gelombang arus pantai dan abrasi seperti yang telah diungkapkan oleh Lasibani dan Eni (2009).

Hasil kegiatan ini dapat dilihat dari dampak edukasi atau arahan yang dilakukan sebelum melakukan kegiatan penanaman mangrove. Secara umum, para peserta telah dapat melakukannya dengan baik. Hal ini terlihat dari kerja sama yang dilakukan peserta saat menanam bibit sesuai dengan jalur penanaman bibit yang telah dibuat dengan jumlah bibit sebanyak 5 batang per titik sesuai dengan arahan yang diberikan sebelumnya. Kemudian, para peserta juga dapat bekerja sama dalam kondisi pasang naik, yang membuat peserta awalnya kesulitan untuk menanam bibit. Hasil kegiatan ini juga dapat dilihat dari luas tutupan (cover) bibit mangrove yang telah ditanam. Pada proses penanaman bibit, dilakukan pengukuran jarak tanam sejauh 1 meter per titik tanam dengan jumlah bibit sebanyak 5 batang, sehingga diperoleh luas tutupannya menjadi $500 \mathrm{~m}^{2}$ untuk seluruh bibit mangrove yang ditanam. Hal ini menyebabkan wilayah penanaman yang awalnya belum ada vegetasi sama sekali seperti yang diperoleh saat observasi awal menjadi ditumbuhi oleh bibit-bibit mangrove, sehingga kegiatan penanaman mangrove ini telah berhasil dilakukan

\section{Kesimpulan}

Kegiatan penanaman mangrove di kawasan Sungai Carang berjalan lancar. Peserta yang terlibat sangat antusias untuk mengikuti kegiatan ini. Kegiatan ini dapat dilakukan oleh siapapun melalui dukungan dari pemerintah, masyarakat, lembaga-lembaga tertentu dan pihak lain yang peduli terhadap kelestarian ekosistem mangrove.

\section{Saran}

Saran yang dapat diberikan untuk kegiatan pengabdian kepada masyarakat seperti ini adalah:

1. Hendaknya kegiatan ini dilakukan oleh siapapun yang memiliki kepedulian terhadap kelestarian ekosistem mangrove, khususnya di daerah Provinsi Kepulauan Riau sebagai salah satu wilayah ekosistem mangrove terbesar di Indonesia.

2. Selain itu, kegiatan ini hendaknya dapat dilanjutkan kembali pada wilayah yang memang membutuhkan konservasi ekosistem mangrove secara berkala.

3. Mempertimbangkan agar kegiatan ini dapat memperoleh pendanaan yang cukup untuk dilanjutkan kembali pada wilayah yang berbeda.

\section{Ucapan Terima Kasih}

Penulis mengucapkan terima kasih kepada LP3M UMRAH yang telah memberikan fasilitas dan dukungan terhadap pelaksanaan pengabdian kepada masyarakat ini. Terima kasih juga kepada Program Studi Pendidikan Biologi UMRAH yang telah mendukung terlaksananya kegiatan pengabdian masyarakat ini. Penulis juga mengucapkan terima kasih kepada mitra kegiatan ini yaitu Banyan Tree dan Balai Pengelolaan Daerah Aliran Sungai dan Hutan Lindung (BPDASHL) Provinsi Kepulauan Riau selaku pihak yang ikut terlibat membantu kegiatan penanaman mangrove ini. Kemudian, penulis juga mengucapkan terima kasih kepada guru, siswa dan mahasiswa se-kota Tanjungpinang yang telah berpartisipasi dalam kegiatan ini dari awal sampai akhir sehingga berjalan dengan lancar.

\section{Referensi}

Bengen, D. (2001). Pengenalan dan Pengelolaan Ekosistem Mangrove. Bogor (ID): PKPSL-IPB. 
JURNAL ANUGERAH, Mei 2020; 2(1): 37-42

\section{e-ISSN 2715-8179}

Irawan, H. (2014). Panduan Penananam Mangrove.

Retrieved from https://www.researchgate.com/publication/329574329

Lasibani, S., \& Eni, K. (2009). Pola penyebaran pertumbuhan "propagul" mangrove rhizophoraceae di kawasan pesisir Sumatera Barat. Jurnal Mangrove dan Pesisir, 10(1), 33-38.

Ledheng, L., \& Yustiningsih, M. (2018). Penanaman mangrove di perairan pantai Tanjung Bastian. Jurnal Pengabdian Masyarakat Bakti Cendana, 1(1), 25-31.

Mulyani, Y., Lewaru, M., \& Haetami, K. (2018). Pemanfaatan dan pelestarian mangrove untuk meningkatkan kesejahteraan masyarakat pesisir Pangandaran. Jurnal Departemen Kelautan, FPIK, Universitas Padjadjaran, 2(11), 976-979.

Mustofa, A. (2018). Praktik pembibitan dan revitalisasi hutan mangrove pesisir Jepara. Journal of Dedicators Community UNISNU Jepara, 2(1), 8-16.

Noor, Y., Khazali, M., \& Suryadiputra, I. (1999). Pedoman Pengenalan Mangrove di Indonesia (2nd ed.). Bogor: Wetlands International Indonesian Programe.

Panca, R. (2019). Enam Puluh Persen Mangrove di Batam Rusak.

Retrieved from Gatra: https://www.gatra.com/detail/news/431333/ekonomi/enam-puluh-persenmangrove-di-batam-rusak.

Riau, B. P. (2019). Potensi Kepri.

Retrieved from https://barenlitbangkepri.com/potensi-kepri/.

Utina, R., Katili, A., \& Retnowati, Y. (2014). Pemanfaatan ekosistem mangrove sebagai media dan sumber belajar IPA biologi di sekolah yang berada di desa sekitar kawasan mangrove. Laporan Akhir KKS Pengabdian Lembaga Pengabdian Masyarakat Universitas Negeri Gorontalo.

Utomo, B., S, B., \& C, M. (2017). Strategi pengelolaan hutan mangrove di desa Tanggultlare Kecamatan Kedung Kabupaten Jepara. Jurnal Ilmu Lingkungan, 15(2), 117-123. 